\title{
PATTERN OF ORBITO-OCULAR TRAUMAS AT BENUE STATE UNIVERSITY TEACHING HOSPITAL: A 4-YEAR RETROSPECTIVE STUDY
}

\author{
Chaha $\mathrm{K}^{1, *}$ Annongu IT ${ }^{2}$, Audu $\mathrm{O}^{3,}{\text { Igbudu } \mathrm{TJ}^{4,} \text { Gbanan DN. }}^{1}$ \\ Department of Ophthalmology ${ }^{1}$, Department of Radiology ${ }^{2}$, Department of Epidemiology and Community Medicine. ${ }^{3}$ and \\ Department of Family Medicine ${ }^{4}$, Benue State University Teaching Hospital, Makurdi.
}

*CorrespondingAuthor: Chaha Kator. Department of Ophthalmology, Benue State University Teaching Hospital .E-mail: katorchaha@gmail.com.+2348034505587

Received date: January $17^{\text {th }}$, 2018, Accepted date: March 02 ${ }^{\text {nd }}, 2018$. Published date: April $20^{\text {th }}, 2018$

\begin{abstract}
Severe orbito-ocular morbidities occur in eye injuries and the causes of these injuries vary with communities. The final outcome of orbito-ocular morbidities depends on early hospital intervention. The aim of the study therefore was to carry out a demographical analysis of orbito-ocular traumas at the Benue State University Teaching Hospital, Makurdi. This was a retro-prospective study. Folders and radiographic images of eye injury patients in the accident and emergency department of the Benue State University Teaching Hospital (BSUTH) between 2013 and 2015 were assessed. Data was analysed and results presented in tables and pictorial form. It was noted in the study that the mean age \pm SD of patients was $29.3 \pm 17.4$ years. Males were mostly affected $(80 \%)$ and students topped the list $(32.5 \%)$. Road traffic accident (RTA) was the major cause of orbito-ocular injury $(47.5 \%)$ and the major orbito-ocular morbidity was blunt or closed ocular injury (37\%). We therefore recommended improved surveillance, adequate road safety measures and increased awareness on the need for early ophthalmologic intervention in order to mitigate the incidence.
\end{abstract}

Keywords: Family, Injuries, Orbito-ocular, Pattern, Trauma.

\section{Introduction}

Orbito-ocular trauma refers to all injuries to the ocular adnexae, the bony orbit and the eyeball. ${ }^{1}$ Trauma to the orbito-ocular structures can result in a number of morbidities and even blindness which adversely affects the family and its dynamics. This aspect of Ophthalmology has been regrettably neglected for so long. Praver referred to these as the 'neglected disorders. ${ }^{2}$ The common orbital and ocular adnexal traumas include the various fractures of the bony orbit, extra-ocular muscle entrapment and injury, optic nerve avulsion, orbital apex syndrome (OAS) and orbital fat loss. Lid lacerations of varying degrees, damage to the lacrimal drainage system and the lacrimal glands are some of the ocular adnexia trauma injuries documented. ${ }^{3}$ The ocular morbidities include conjunctival lacerations, corneo-scleral lacerations,

irido-ciliary tear or irido-dialysis, traumatic cataract, vitreous haemorrhage, retinal tears, retinal detachments, commotio retinae, optic nerve avulsion and the optic neuritis with eventual optic atrophy and blindness. 4

The Birmingham Eye Trauma Terminology System (BETTS) classification is universally accepted to classify the mechanical eye trauma cases. ${ }^{2,3}$ and defines the various tissues in the eyeball involved in mechanical eye injury. ${ }^{5}$ Causes of orbito-ocular trauma ranges from road traffic accidents (RTA), Industrial accidents, occupational hazards, domestic violence/accidents, and wars among others. ${ }^{6}$ Trauma to the orbito-ocular tissues generally have bleak visual outcome. The proximity of the eye care 
facilities to patients, good family support, the interval between the time of injury and the time of visit to the health facility and the ophthalmological interventional procedures are all of prognostic value to the victims. ${ }^{7}$ There is paucity of data on orbital, ocular/adnexal trauma, particularly the epidemiological studies in our environment. ${ }^{8}$

The study therefore aims to analyze the orbito-ocular traumas at the Benue State University Teaching Hospital, Makurdi and assess visual acuity pre and post intervention.

\section{Materials and Methods}

This is a 4-year retrospective study of all eye injury patients that presented to the accident and emergency department of BSUTH between 2013 and 2016. The patient's folders and their corresponding radiological images acquired at presentation were analysed with respect to age, sex and occupation. Cause(s) of injury, type of orbito-ocular morbidity based on
BETT's classification, the time interval at presentation, visual acuity pre and immediate post intervention, and the type of intervention carried out were also assessed.

\section{Statistical Analysis}

Data was analysed for various variables using Statistical Package for Social Sciences version 16(SPSS, Inc, Chicago, Illinois, USA) and Microsoft excel and the results were presented in tables and pictorial form. The level of statistical significance was set at $p<0.05$. Consent was sought and obtained from the Hospital Research Ethical Committee.

\section{Results}

A total number of forty eyes $($ Right $=25$, Left $=15)$ were reviewed with age range of patients from 1-60 years and majority of them $(22.5 \%)$ were between 21-30 years of age (Table 1).

Table 1. Age Distribution

\begin{tabular}{lll}
\hline Age group (Years) & Frequency & \% \\
\hline $\mathbf{1 - 1 0}$ & 8 & 20.0 \\
$\mathbf{1 1 - 2 0}$ & 6 & 15.0 \\
$\mathbf{2 1 - 3 0}$ & 9 & 22.5 \\
$\mathbf{3 1 - 4 0}$ & 5 & 12.5 \\
$\mathbf{4 1 - 5 0}$ & 6 & 15.0 \\
$\mathbf{5 1 - 6 0}$ & 6 & 15.0 \\
Total & 40 & 100 \\
\hline
\end{tabular}

Students (invariably younger age group) were mostly implicated accounting 32.5\% (Table: 2)

Table 2.Various Occupations of Patients

\begin{tabular}{|c|c|c|}
\hline Occupation & Frequency & $\%$ \\
\hline Pupil & 7 & 17.5 \\
\hline Student & 13 & 32.5 \\
\hline Artisan & 1 & 2.5 \\
\hline House wife & 1 & 2.5 \\
\hline Farming & 6 & 15.0 \\
\hline Business & 4 & 10.0 \\
\hline Civil Servant & 8 & 20.0 \\
\hline
\end{tabular}


Conservative management was the major intervention done. Other intervention included corneo-scleral repair (22\%), cataract extraction among others (Table 3 ).

Table 3: Intervention carried out

\begin{tabular}{lll}
\hline Interventions & Frequency & Percentage \\
\hline Conservative Management & 14 & 35.0 \\
Corneo-scleral Repair & 9 & 22.5 \\
Adnexal Repair & 7 & 17.5 \\
Globe Removal & 6 & 15.0 \\
Cataract Extraction & 2 & 5.0 \\
Foreign Body Removal & 1 & 2.5 \\
Combined (cataract+glaucoma) surgery & 1 & 2.5 \\
Total & 40 & 100.0 \\
\hline
\end{tabular}

Of the 40 eyes affected, only 10 (25\%) had normal vision before intervention but this figure improved to 22 (55\%) after intervention (Table 4 ).

Table 4: Visual acuities Pre and Post Intervention

\begin{tabular}{lllll}
\hline Visual Acuity (VA) & Left Eye (N=25) & \multicolumn{3}{l}{ Right Eye (N=15) } \\
\cline { 2 - 5 } & At presentation & Post Intervention & At presentation & Post Intervention \\
& Freq. $(\%)$ & Freq. $(\%)$ & Freq. $(\%)$ & Freq. $(\%)$ \\
Normal Vision & $4(16.0)$ & $13(52.0)$ & $6(40.0)$ & $9(60.0)$ \\
Visual Impairment & $0(0.0)$ & $2(8.0)$ & $0(0.0)$ & $1(6.7)$ \\
Severe Visual Impairment & $3(12.0)$ & $2(8.0)$ & $0(0.0)$ & $1(6.7)$ \\
Blindness & $13(52.0)$ & $6(24.0)$ & $5(33.3)$ & $4(26.7)$ \\
VA $^{-} /$Loss to follow up & $5(20.0)$ & $2(8.0)$ & $4(26.7)$ & $0(0.0)$ \\
Total & $25(100.0)$ & $25(100 . .0)$ & $15(100.0)$ & $15(100.0)$ \\
\hline
\end{tabular}

VA': Visual acuity not done.

By sex, the males were 32 in number (80\%) Fig 1.

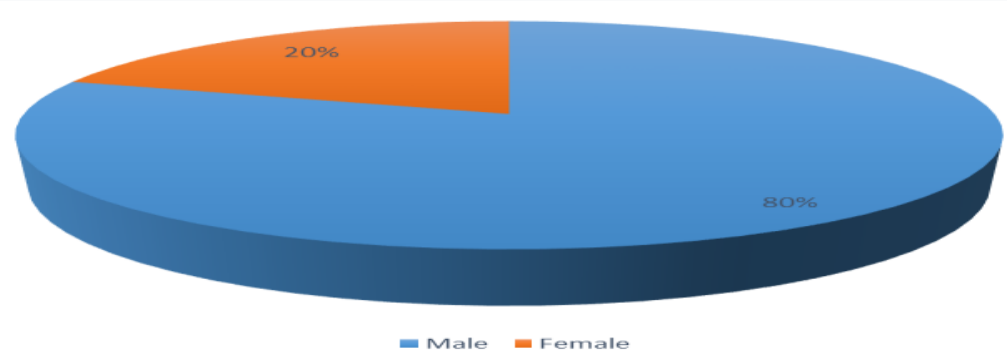

Fig 1.Sex Distribution of Patients. 
Road traffic accident was the major cause of orbito-ocular injury constituting $47.5 \%$ (Fig. 2).

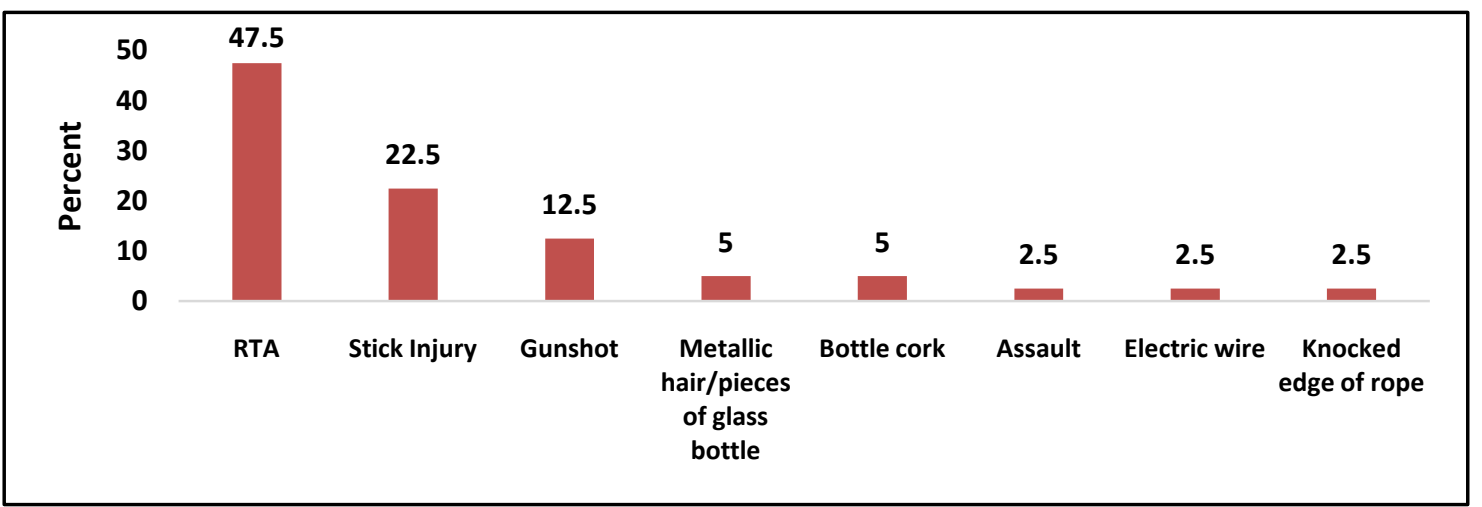

Figure 2: Percentage Distribution of causes of Injury.

The major orbito-ocular morbidity was blunt or closed ocular injury constituting $37.5 \%$ followed by multiple orbito-ocular tissue involvement (Fig: 3).

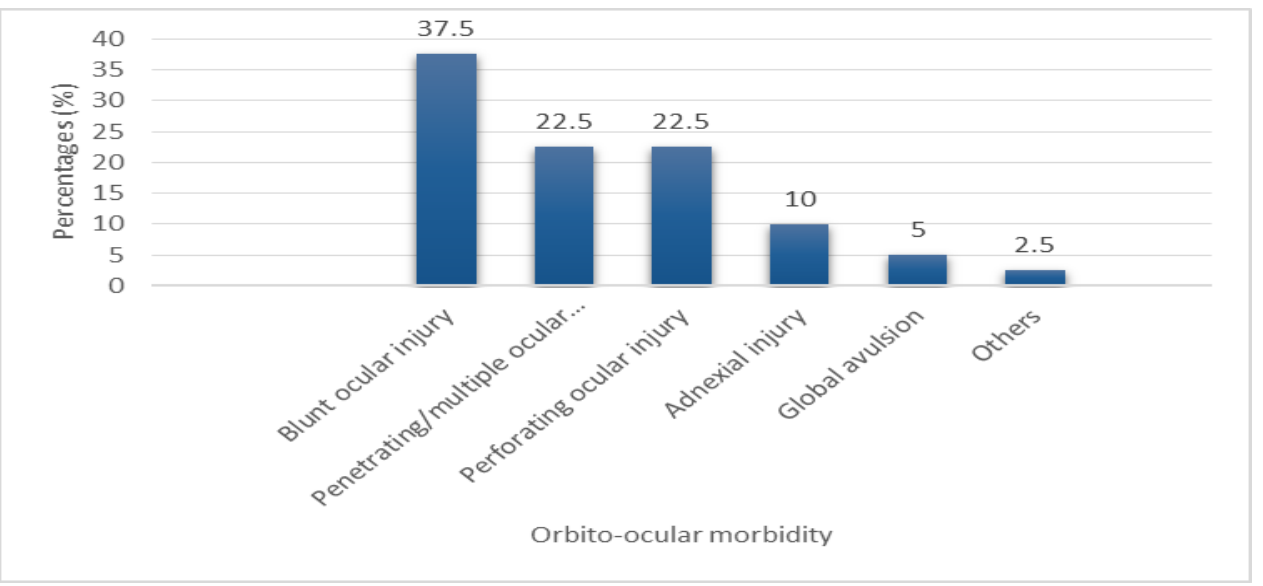

Figure 3: Percentage Distribution of orbito-ocular morbidity at presentation.

Sixteen patients (40\%) presented to the Ophthalmologist within 24 hours of incidence and fifteen (37.5\%) between day 2-7 (fig 4).

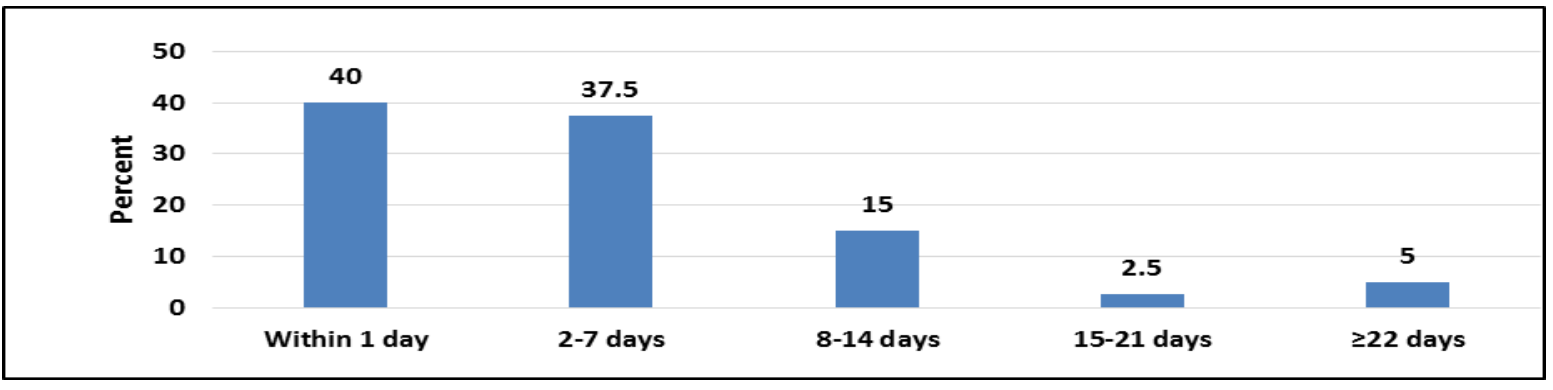

Fig 4. Time interval at presentation 


\section{Discussion}

Although the eyeball represents only $0.3 \%$ of the total surface area on the human body, loss of vision in one or both eyes has been classified as a $24 \%$ or $85 \%$ disability, respectively. ${ }^{8}$ Injury to the face involving the orbito-ocular tissues with attending family challenges remain the most serious public health problem in the developed world ${ }^{9}$ and the socio-economic burden due to orbito-ocular injuries is huge and requires concerted efforts aimed at prevention of the scourge. ${ }^{10}$

Almost all literature is in agreement over the higher prevalence rate of traumatic oculo-orbital trauma in the males ${ }^{11}$ This collaborates with our study in which out of the 40 patients reviewed, 36 (80\%) were males. Similarly in most cases of orbito-ocular trauma, more than half of ocular injuries involve people of less than 30 years. ${ }^{7,9}$ This also agrees with our work which showed that the age group less than 30 years is mostly implicated. Possible reasons for these could be due to the fact that men of younger age group are involved more in violent activities (including intimate partner violence among family members), travelling, wars, and sports among others.

The orbital fractures usually are a consequence of mid-facial fractures and most facial injuries involving the orbit are caused by road traffic accidents and violent assaults. ${ }^{8}$ This also agrees with our work in which RTA accounted for $47.5 \%$ of cases. In another study in Chaoshan region however, work-related injuries of the eye accounted for the highest reason for orbito-ocular injuries and majority occurred in the male gender. ${ }^{12}$ This probably could be due to better road network and higher industrialised nature of the country where the study was done compared to our study area accounting for more cases of work related region being recorded. Domestic violence including intimate partner violence among family members, animal bites like dog bites, has also been reported in a certain study. ${ }^{13}$

Generally, most orbito-ocular trauma affect more than one eye tissues and sites as highlighted by the work done by Rafindadi, et al in Nigeria at Ahmadu Bello University Teaching Hospital, Zaria. ${ }^{14}$ Similarly in our study, multiple tissue sites were affected in the same eye as evidenced by a significant proportion of about $22.5 \%$ and was encountered mostly in patients with penetrating eye injuries. However blunt ocular injury was the most encountered injury in this study. Usually, orbitoocular trauma has discouraging outcome. In our study, even though $77.5 \%$ of our patients presented in the first one week ( $40 \%$ in the first 24 hours and $37.5 \%$ from the 2 nd to 7 th day), only 10 (50.7\%) of the total $18(85 \%)$ of blindness was restored after intervention. In the visual impairment (VI) category, there was worsened outcome and in the severe visual impairment (SVI) category, improvement was noted only in one patient (8\%) in the left eye despite intervention. Normal vision (NV) was seen in $13 \%$ in the left eye after intervention against $4 \%$ at presentation and $9 \%$ in the right eye against $6 \%$ at presentation.

\section{Conclusion}

RTA was the commonest cause of orbito-ocular traumas in our study and the younger age group was the most affected. Blunt ocular traumas and multiple ocular tissue injuries were the commonest morbidity recorded, a number of which, without early intervention, could end in poor visual outcome.We recommend improved surveillance, adequate road safety measures \& increased awareness on the need for early ophthalmologic intervention.

\section{Conflict of Interest}

Authors have declared that no conflicts of interests exist.

\section{References}

1. Ken YL, Philip N, Julio CE, Jeremiah PT. Imaging in orbital trauma.Saudi J Ophthalmol. 2012; 26(4): 427-432.

2. Praver L. Eye trauma. The neglected disorder. Arch Ophtalmol 1986; 104:1452-3.

3. Gonnering RS. Ocular adnexal injury and complications in orbital dog bites. OphthalPlastReconstr Surg. 1987; 3(4):231-5.

4. Kuhn F, Morris R, Witherspoon CD, Heimann K, Jeffers JB, Treister G. A standardized classification of ocular trauma Ophthalmology.1996; 103(2):240-3. 
5. Kuhn F, Morris R, Witherspoon CD, Mester V. The Birmingham Eye Trauma Terminology system (BETT). J FrOphtalmol 2004; 27(2):20610.

6. Reyes JM, Vargas MFG, Rosenvasser J, Arocena MA, Medina AJ, Funes J. Classification and epidemiology of orbital fractures diagnosed by computed tomography. Head and Neck/Leading article. Rev. Argent. Radiol. 2013;77(2):139-146

7. Sayjal J, Patel MD, Vinay A, Shah MD. Ocular penetrating and perforating injuries. 2014[cited 21 December 2014]. Availablefrom:http://www.eyewiki.aao.org/Ocul ar_penetrating_and_perforating_injuries/

8. May DR, Kuhn FP, Morris RE, Witherspoon CD, Danis RP, Matthews GP, et al Mann L The epidemiology of serious eye injuries from the United States Eye Injury Registry.Graefes Arch ClinExpOphthalmol. 2000; 238(2):153-7.

9. Thylefors B. Epidemiological patterns of Ocular Trauma. Clinical \& Experimental Ophthalmology. 1992; 2(20).

10. Feldman BH, Patel SJ. Shah VA. Ocular penetrating and perforating injuries: [cited 4 December 2017].

Availablefrom:http://www.eyewiki.aao.org/Ocul ar_penetrating_perforating_injuries

11. Nagib du Toit, Hamza M, Colin C. Visual outcomes in patients with open globe injuries compared to predicted outcomes using the Ocular Trauma Scoring system. Int $J$ Ophthalmol. 2015; 8(6): 1229-1233.

12. He C, Liping L, Mingzhi Z, Hongni L. Epidemiology of Paediatric Ocular Trauma in the Chaoshan Region, China. 2013; 8(4):20012010.

13. Uysal Y, Mutlu FM, Sobac1 G Ocular trauma score in childhood open-globe injuries. J Trauma. 2006; 65(6): 1284-1286.

14. A, Victoria A $P$, Dominic $C$, Fatima A $M$. Orbital and ocular trauma at Ahmadu Bello University Teaching Hospital, Shika-Zaria: A retrospective review. Annals of Nigerian Medicine2013; 7 (1): 20-23. 